\title{
Research on Operation Dilemmas and Innovations of Chinese Insurance Companies
}

\author{
Yue Gu \\ Statistic \& Mathematics Major, College of Liberal Arts and Science, University of lowa, lowa, \\ IA52245, America
}

Keywords: Enterprise operation, Innovation operation, Optimization research

\begin{abstract}
The purpose of this paper is to analyze the root cause of the rapid growth of A group enterprise in recent years through the analysis and comparison of operating mode of $\mathrm{A}$ in China's insurance companies combined with the new operation framework and models. Combined with A group's financial report for 2012 -2015, the paper analyzes A group's balance sheet, consolidate income statement and audit report. According to the integration and comparison of A group's innovation management, we find the problems in the development process and put forward the corresponding solutions to draw the future development strategy.
\end{abstract}

\section{Theory and Literature Review}

Enterprise innovation is according to the development trend of the market demand for production and business, with the market to adapt to the needs of the product, and make full use of their own resources and to optimize the allocation of social resources, from all aspects of the management of enterprises to create and innovate. Its basic content includes: system innovation, technology innovation, management innovation. Overall, innovation cannot be separated from the main innovation, everyone is the main body of innovation. The enterprise is the main innovation in the market economy, for the enterprise, innovation can be divided into product innovation, technological innovation, market innovation, marketing innovation, thinking innovation, management innovation.

The characteristics of enterprise innovation are: creativity, risk, high efficiency, systematic and comprehensive, timeliness and practicability. Among them, the most important is the high efficiency. In today's society, it is important to pay attention to the effective use of time cost, the enterprise must use limited time and cost to achieve the highest effect. Therefore, in order to improve the efficiency of the purpose of the development of a variety of new technologies. Therefore, high efficiency is the basic characteristic.

The basic elements of enterprise innovation: vision, resources, ways. The three are interrelated and interconnected to form the whole of enterprise innovation. Therefore, the enterprise innovation is actually a kind of combination with the dialectical thought of philosophy.

The method and the approach of innovation: the importance of strategic management, constructing "enterprise ecology", adjust the organizational structure, the establishment of human culture, strengthen knowledge management, cultivate the occupation of entrepreneurs, accelerate system innovation, system innovation to promote the innovation of management.

Opportunity for Innovation: unexpected opportunities, technological changes in production or management, population changes, changes in the macroeconomic environment, the transformation of cultural mentality, the existence of disharmony, the actual needs of the work. Combined with the status quo of the contemporary social variability, enterprises can seize the opportunity to realize the qualitative change of enterprise innovation.

The construction of innovative enterprise strategy: enterprises should establish independent innovation organization safeguard mechanism, strengthen the combination of technological innovation system, strengthen brand innovation, innovation and the introduction of effective combination, to strengthen international exchanges and cooperation, build a independent innovation talent team, strengthen IPR protection, establish and improve the independent innovation of 
enterprises the system of laws and regulations, the government should create a good environment for enterprise independent innovation.

\section{Current Situation and Problems Analysis}

Development Present Situation of A Company. According to the annual report of A group, in May 27, 1988, A insurance company was established as a joint stock insurance company. In 1994, A group introduced Morgan and Goldman Sachs, the two foreign shareholders, to become a joint venture financial institutions in China and the United States and China, the group of. In the same year, China A group took the lead in the introduction of individual life insurance marketing system, to create China's first batch of individual life insurance business. 1995, A group set up securities limited liability company. 1996, A Group acquired the Pearl River Delta financial trust ICBC. 2002, HSBC Group A group. 2003, China A Group acquired a bank in Fujian, its banking business to expand. 2004, A group's overall overseas listing, greatly expanding the company's capital strength. 2006, A group's national operations management center in Shanghai officially began operations. In the same year in July, A Group acquired a commercial bank in Shenzhen. 2007, A group listed on the Shanghai stock exchange. 2011, A group has become the controlling shareholder of the deep development, further development of the merger of the original A group to further absorb the bank under the jurisdiction of the formal establishment of a national banking business layout. 2012, Lujinsuo was founded. A began a comprehensive layout of Internet banking. 2014, according to Millward Brown released the world's top 100 brands, A group enterprise with $\$ 12$ billion 400 million brand value, ranking the world's insurance industry leader.

At present, A group has a large number of business, in terms of its core insurance business, A's insurance companies, including life insurance, property insurance, health insurance, pension insurance. Among them, the financial rescue including flagship store car insurance, travel insurance, children's insurance, property insurance, health insurance, accident insurance, pension insurance, cancer insurance, critical illness insurance. After that, pay attention to its banking business, including banking, credit cards, personal business, corporate business, small businesses, loans, deposits. For all walks of life, from individual customers to corporate customers, all things, while for risk control, but also to provide guaranteed income, high-yield, low-risk type of specific financial management, take care of all types of customers. Finally, for its investment business, including securities, real estate, trust, fund, information management, futures, private equity.

Internal competition mainly refers to the three-line competition of insurance, banking and investment, and the competition of each department under the linear development. According to the annual report of A group, improving the risk management framework and risk management communication mechanism, and actively explore and study the risk preference system, establish the concentration risk management system, establish effective risk management system, continuous improvement and development of quantitative risk management technology and models, comprehensive risk management for each subsidiary company. Therefore, in the face of the status quo of internal competition, the various departments of the line are also constantly improving their own risk control capabilities. On the other hand, we focus on the market risk and use the market price risk value method to estimate the risk exposure.

In the face of competition in the same industry, due to the A line of three lines, equal to the need for competition in both directions at the same time in three. China Life Insurance Group, the bank has the Bank of China, the investment industry has Morgan Stanley. On the one hand, due to the three lines of competition at the same time, the competitive pressure, but on the other hand, it is precisely because of the industry benchmarking enterprises, can learn and learn the case is also very much. Therefore, in the face of external competition, competitive pressures in a timely manner challenges, but also opportunities. If you can correctly combine the advantages of challenges and opportunities, the three line of development is likely to be mutually exclusive and thus become complementary to the three lines. 
Problems Analysis of A Group Enterprise. The first is the division of the functions of the corporate sector is too overlap. Due to the repeated function of the Department, the internal efficiency of the group is likely to be greatly limited, it seems that each function is covered, but in fact it is another form of constraints. Due to the development of various departments need to pay attention to, the development costs have been greatly increased.

The second is the development strategy of risk control and underwriting function problems. Due to the emergence of the new prediction technology, the development of A group needs a lot of data theory as the support, for the inherent interest rate risk of the maturity of the investment, risk assessment, but also need the support of the data. Therefore, we should not only pay attention to the high-level decision-making, but also need to focus on the customer base. Therefore, in the face of the focus of the A group on the decision-making power of the board of directors, A group should be appropriate decentralization, improve the grassroots power functions, so as to have more practical significance with the times.

On the other hand, we see that because of its large business, management is difficult, the organizational structure is very complex, therefore, it will become a stumbling block to the A group on the path of development, to some extent hindered the development of road A group.

Finally, the division of the business division. For example, such as "A group asset allocation series" business system. In fact, the confidence of enterprising and worry income type is the existence of a certain business overlap. Focus on customer group diversity and development covering all aspects of the business is a good way to development, but if we can further integrate the business scope, will be more efficient to enhance the customer experience, and choose relevant business in users began to have displeasure. This is a strategic point of concern for both internal and external competition.

The problems can be summarized as:

1) there are too many types of business, and there is overlap of business types;

2) the Department set up too much, there are overlapping powers;

3) department management resources waste, high communication costs;

4 the lack of reasonable interaction between the top management and the grass roots;

5 data acquisition technology needs to be further strengthened.

\section{Innovative Optimization and Revelation}

Optimizations and Solutions of Development Problems of A Group Enterprise. Too many types of business, business categories overlap: integration of repeat business, improve business efficiency, ensure group differences in customer experience and at the same time, improve the efficiency of business development; improve the derivative function of each business, based on a single business understanding, further enhance the implementation of multi business.

The Department is too much, there are overlapping functions: to strengthen the functions of one to one relationship, the clear division of functions, reduce unnecessary departments docking process consultation and cross sectoral integration process; alternate authority departments, can realize to unify many departments, namely in the setting of the door under the premise, can the detailed internal refinement departments, and departments by the higher administrative department of unified management, combined with internal and external management mechanism under the condition of reducing overlapping functions. Department of management resources are wasted, the high cost of communication: the integration of the Department set up after the formation of a unified, efficient feedback mechanism, the unified mechanism, improve the utilization of enterprise resources efficient communication, reduce the communication cost; the working layer of the work held regular meetings and forum feedback, timely understanding of the meet the demands of work and working layer in the process, and timely improve future strategy, reduce the potential cost of communication in the future.

The lack of interaction between the top management of the enterprise and the grass roots of the masses: to increase the opportunities for high-level contact with the grassroots, through data analysis, questionnaire, a better understanding of the needs of the grassroots. At the same time, the enterprises 
should strengthen high-level decision-making and middle-level manager's timely communication, middle managers can have instant feedback on the top management of the grassroots workers thought; carry out corporate executives and grassroots development activities or senior management concept of propaganda, strengthen high-level understanding of grassroots.

The work of data acquisition should be further strengthened: to strengthen the core technology innovation and intellectual property protection, strengthen the collection of data and pay attention to the grassroots. To improve the study of foreign well-known case, strengthen domestic and international cooperation, learn from foreign advanced technology, the introduction of foreign returnees and appropriate technical personnel; improve the core decision-making ability of underwriting, decision-making, improve the risk judgment ability at the same time, the process of the specific risk control function is applied to the three line in the development. The development of enterprises to form an organic whole.

Relevant Revelations of Operation Strategies in the Future. The first is to carry out the core technology for underwriting, focusing on risk control of financial business. Strengthen the role of risk control in the overall value chain, to ensure the risk control of business income. Second, is to carry out a close connection with the grassroots masses of diversity business. Only by mastering the masses, we can grasp the core of the revenue, the fracture of the high level and the basic level is not in line with the trend of the future. Third, is to focus on the use of big data era background, the predictability of the data for the future. In the A group to further carry out its diversity of business at the same time, for example, do a good job of data collection, through the professional analysis of data to achieve accurate prediction of the future development of the times. Fourth, it is necessary to rationally integrate the various departments within the enterprise, so that they complement each other and compete with each other. Reduce the intersection of departmental functions, reduce the cost of communication, and strengthen the common benefits of the interaction of functions. Fifth, it is necessary to maintain the development of the A group with other differences in the same industry, there are differences in the development of different. Only in many peers to maintain their unique business differences, in order to more firmly grasp the customer, to achieve long-term development. Sixth, it is necessary to pay attention to policy changes at home and abroad. In the context of the integration of politics, economy and culture, it is natural to realize the development of the enterprises that conform to the trend of the world. Seventh, it is necessary to pay more attention to corporate brand image. According to the theory of enterprise innovation, establish a brand image is one of the most important elements of development, the development of innovative enterprises therefore, continue to pay attention to at home and abroad to establish the brand image of the A group, A group, let the real from the domestic to the world.

\section{Conclusion}

Under the background of global economic integration, we need a new way for the development of Chinese enterprises. Through the integration of international innovation and development factors, we can learn how to avoid cultural conflicts, how to correctly deal with cultural differences on international business enterprise, how to strengthen the effect of innovative enterprise innovation and so on. Therefore, it is very important to analyze the innovation management mode and international operation mode of the enterprise.

\section{References}

[1] Bian Wenlong, Wang Xiangnan, The Effects of Investment Business of Property Insurance Companies on Operation Efficiency in China [J]. Journal of Finance and Economics, 2016, 42(7): 16-27.

[2] Huo Lianhong, A Study of the "Customer's Demand-Oriented” Transformation and Innovation of Insurance Companies [J]. Finance Forum, 2016(1): 32-39. 
[3] Fu Chunhong, Reflections on Innovation in Products and Services of Property Insurance Companies [J]. Journal of Tonghua Normal University, 2013, 34(1): 41-43.

[4] Sun Rong, Wang Chao, Comprehensive Evaluation of the Performance of Insurance Companies in China [J]. Insurance Studies, 2013(1): 49-57. 